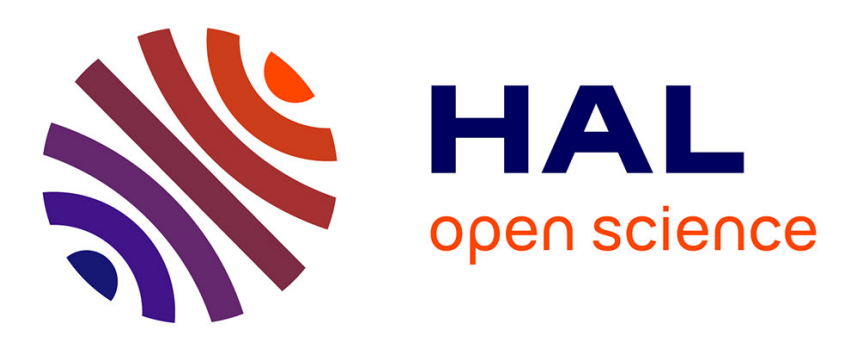

\title{
Why Do Some Places Succeed When Others Decline? A Social Interaction Model of Cluster Viability
}

\author{
Jérôme Vicente, Raphaël Suire
}

\section{To cite this version:}

Jérôme Vicente, Raphaël Suire. Why Do Some Places Succeed When Others Decline? A Social Interaction Model of Cluster Viability. Journal of Economic Geography, 2009, 9 (3), pp.381-404. hal-00418539

\section{HAL Id: hal-00418539 \\ https://hal.science/hal-00418539}

Submitted on 20 Sep 2009

HAL is a multi-disciplinary open access archive for the deposit and dissemination of scientific research documents, whether they are published or not. The documents may come from teaching and research institutions in France or abroad, or from public or private research centers.
L'archive ouverte pluridisciplinaire HAL, est destinée au dépôt et à la diffusion de documents scientifiques de niveau recherche, publiés ou non, émanant des établissements d'enseignement et de recherche français ou étrangers, des laboratoires publics ou privés. 


\title{
Why do some places succeed when others decline? A social interaction model of cluster viability
}

\author{
Raphaël Suire* and Jérôme Vicente**
}

\begin{abstract}
One of the most convincing explanations papers generally provide concerning clusters in knowledge-based economies refers to the geographically bounded dimension of knowledge spillovers. Here, we shall underline that location decision externalities precede local knowledge spillovers in the explanation of cluster aggregate efficiency, which thus requires us to focus on the sequential process of location and the nature of interdependences in location decision-making. To that end, we mean to associate cluster emergence with the formation of locational norms, and to study the critical parameters of their stability. These parameters relate to the type of decision externalities among more or less cognitively distant firms, which influences the weight and the resulting ambivalent role of knowledge spillovers at the aggregate level of clusters. We suggest two theoretical propositions which we test within a simple and general norm location dynamics modeling framework. We then proceed to discuss the results so obtained by comparing them with an emerging related literature based on the life cycle and viability of clusters.
\end{abstract}

Keywords: clusters, location under decision externalities, cognitive distance, knowledge spillovers JEL classifications: D83, L86, R12

Date submitted: 16 January 2008 Date accepted: 21 November 2008

\section{Introduction}

Innovative clusters have been the subject of growing attention based on the role they play in the knowledge-based economy (Martin and Sunley, 2003). Most of the papers generally refer to the geographically bounded dimension of knowledge spillovers (Breschi and Lissoni, 2001). Studies of local knowledge spillovers are particularly suited to explain the causal relations between existing agglomerations of activities and aggregate performance at regional level, but they are less relevant to explain the reasons why some clusters succeed whereas others decline. Indeed, some of the 'Silicon- or 'Valley-type' clusters, which were fashionable in the late nineties and during the Internet bubble, have since declined [such as the French Silicon Sentier or the well-known Silicon Alley (Dalla Pria and Vicente, 2006; Vicente and Suire, 2007)], while others (such as the emblematic Silicon Valley or the French Telecom Valley) have stood up to

*CREM-CNRS, University of Rennes 1, 7 place Hoche, 35065 RENNES Cedex - France. email<raphael.suire@univ-rennes1.fr>

**University of Toulouse, LEREPS, Manufacture des Tabacs, 31000 TOULOUSE - France.

email<jerome.vicente@univ-tlse1.fr> 
the aftermath of the Internet bubble's crash, exhibiting a strong dynamic stability. The geographical charisma (Appold, 2005) clusters display is not a guarantee of their collective efficiency and geographical proximity between firms may, under specific conditions, give rise to fragility and instability.

The purpose of this article is to show how the intrinsic performance of clusters can be analyzed through a focus on the sequential process of location and the nature of interdependences in location decision-making. To that end, we set out to associate cluster emergence with the formation of locational norms, and to study the critical parameters of their stability. These parameters refer to the type of decision externalities among more or less cognitively distant firms that influences the weight and the resulting ambivalent role of knowledge spillovers at the aggregate level of clusters. We then propose a dynamic approach, in line with an evolutionary economic geography framework (Boschma and Martin, 2007), in that it focuses on a complex micro-macro process of location decision-making, which implies an out-of-equilibrium perspective (Boschma and Frenken, 2006). Such a framework makes it possible to capture interesting cluster pathways, such as path dependence, lock-in, lock-out and phase transitions. More precisely, we are close to an emerging related literature based on the life cycle of clusters (Menzel and Fornahl, 2007; Ter Wal and Boshma, 2007) in order to better capture why and how clusters, as well as the collective advantages associated with them, change over time.

Sections 2 and 3 provide general considerations and definitions on knowledge interactions and the colocation process under decision externalities. Section 4 develops a set of testable propositions on the parameters of cluster stability. Section 5 puts forward a simple norm location dynamics model under decision externalities, presents the simulation results and discusses their relevance compared to the main stylized facts on cluster aggregate efficiency.

\section{Uncertainty, legitimacy and knowledge interactions in location decision-making}

The literature on clusters stresses the role of knowledge interactions among complementary firms (Cooke, 2001), especially in high-tech sectors where knowledge generation depends on the combination of existing and fragmented knowledge (Antonelli, 2006). A striking argument is that geographical proximity favors tacit knowledge interactions among cognitively distant firms. Following Nooteboon (2000), a certain amount of cognitive distance between partners gives rise to a higher probability of knowledge creation than an excess of cognitive proximity, ${ }^{1}$ but it also leads to some misunderstanding situations which require frequent meetings. Thus, geographical proximity increases the respective knowledge absorption capabilities of partners, and so favors accessibility to external knowledge. However, cluster embeddedness is not a panacea for firms' innovative performance due to the risks of knowledge under-appropriation and unintended knowledge spillovers 
proximity to other firms can imply. These risks are lower if cognitive distance is strong so that firms operate within markets that are differentiated enough to avoid the knowledge hold-up phenomenon (Kogut, 1988). High-tech clusters around the world draw their geographical charisma from this knowledge network effect which engenders permanent novelty in the early stages of a technology's life cycle. On the other hand, too weak a cognitive distance may appear as a handicap when there is not a sufficient amount of variety introduced into the networks of innovative firms. In that case, clusters may thus come to be locked in an under-competitiveness syndrome as a result of an excess of conformism (Boschma, 2005).

Nevertheless, a more marginal part of the literature highlights other features of the regional clusters' geographical charisma which, in some respects, are at variance with the increasing literature on local knowledge networks. These features refer to the interplaying uncertainty decrease and search for legitimacy in location decisionmaking (Appold, 2005; Dalla Pria and Vicente, 2006; Vicente and Suire, 2007). Appold (2005) shows that the agglomeration of innovative firms in US science parks takes place without there being any network effects or functional knowledge interdependences implied. Clusters emerge and grow through 'mimetic isomorphism' (Di Maggio and Powell, 1983) leading to collective legitimacy, and not necessarily to collective and organizational efficiency. Uncertainty in location decision-making can be identified as the main reason accounting for both the search for legitimacy and herding locational behavior. Appold notes that 'a manager could conclude that the number of successful laboratories at a particular site is an indicator of its productivity' (p. 21), without there being any further information on the intrinsic characteristics of the territories or on the site's relational potential. The location of cognitively close firms in an area is perceived as a signal for the others, which produces a so-called bandwagon effect (Leibenstein, 1950). Dalla Pria and Vicente (2005) and Vicente and Suire (2007) have identified a similar phenomenon in the emblematic French case of the Silicon Sentier, a cluster gathering over 300 pure players and Internet companies in a forsaken area of central Paris. In this peculiar case, the location of Yahoo-regarded as a fashion leader in the sector-in 1997, had contributed to the construction of a locational norm (or 'signal location') which provided new entrants in e-business with the legitimacy they did not have due to their recent creation. Furthermore, in this case, the weakness of knowledge relations and the low cognitive distance between firms appeared as a key feature of this end of nineties successful ICT cluster.

At this stage, the wide-ranging proposition of this article is that the dynamic stability of clusters depends on the nature of the sequential process of colocation, as well as on the nature of decision externalities at play in the aggregative location process. More precise propositions will be defined hereafter, which will emphasize the critical parameters concerning the very upstream phase of the motives for location decisionmaking. The correlative idea is that knowledge spillovers could have differentiated effects according to whether firms follow the location of others (relevant predecessors) in order to (i) reduce uncertainty among location alternatives and increase their legitimacy, or (ii) find partners and have access to external knowledge. Finally, as underlined by Ter Wal and Bohsma (2007): 'The uncertainty and lack of knowledge about who are the main players in the field initially lead to a highly unstable network structure.' 


\section{Social interactions under mimetic pressures}

Why do agents converge on location decision-making? One of the most promising social interaction mechanisms accounting for such a convergence process stresses the role played by mimetic behaviors and decision externalities. Social interactions based on mimetic behaviors have been the subject of a growing literature in economics (Banerjee, 1992; Bikhchandani et al., 1992, 1998; Manski, 2000; Orléan, 2006), but also in sociology (Granovetter, 1978; DiMaggio and Powell, 1983; Hedstrom, 1998; Strang and Macy, 2001; Watts, 2006). The basic idea is that interactions are always sequential. This assumption is crucial for at least one reason: it permits to introduce into the interaction mechanisms the possibility for agents to observe the decision of others, and more generally to enter the black box of decision externalities leading to cumulative processes.

We can distinguish two kinds of motives for agents to adopt mimetic behaviors or to converge upon the same decision, irrespective of geographical considerations at this stage. Each of these motives involves different properties of aggregate outcomes in terms of collective behavior stability.

The first of these motives relates to uncertainty and legitimacy. When agents face uncertainty in their decision-making, it would seem rational for them to emulate others and to decide on the basis of an observational-learning process (Manski, 2000). Bikhchandani et al. (1992, 1998) have developed a herding behavior model where observation of others is the key criterion of (sequential) interactions. Bikhchandani et al. show that, under specific conditions, agents can converge quickly in terms of decision making, which leads to conformity effects such as fads or fashions. It is important to point out here that this convergence process - the so-called informational cascade - rests on very little information, which is sometimes limited to the only information available through the private signals of the first adopters in a community. In the well-known sociological approach of DiMaggio and Powell (1983), uncertainty also appears as a strong source of mimetic interactions in the dynamics of collective behaviors. DiMaggio and Powell try to capture convergence processes in decision making through the concept of institutional isomorphism, which can be defined as the constrained process that forces an agent in a population to resemble the other agents experiencing a similar economic or social context. As a matter of fact, organizations such as firms can converge upon the same organizational design and market strategyand so upon a low cognitive distance (Nooteboon, 2000) - owing more to a mimetic process than to sometimes costly experimentations and explorations of organizational alternatives or market niches. The need for legitimacy is the corollary of these uncertainty-based mimetic interactions. Essentially developed in sociology, this idea is introduced as well in the model of Bikhchandani et al. through the so-called notion of 'fashion leaders', i.e. agents having such an expertise capacity and reputation that they can influence the trajectories of collective choices in the early stages of or during the clustering process. It would be more legitimizing to emulate other agents that may be acknowledged as being endowed with a strong reputation and legitimacy. Legitimacy is a strong source of rational imitative behaviors in the works of Hedstrom (1998) too. It would be rational to follow others in view of the belief according to which imitation is a useful strategy to obtain valued positions or resources, and to avoid being marginalized within communities. In a more institutional way of thinking, DiMaggio and Powell insist on the fact that mimetic processes leading to institutional isomorphism are based 
on the argument that 'organizations tend to model themselves after similar organizations in their field that they perceive to be more legitimate or successful' (p. 152). They put forward the idea that agents are more likely to follow the decisions of well-reputed other agents than to assess whether these decisions enhance efficiency or not. So, uncertainty and legitimacy appear as strong motives giving rise to collective behaviors, and they certainly contribute, to a certain extent, to the above discussed low cognitive distance.

The second motive explaining convergence in decision making through sequential and mimetic processes refers to the question of accessibility to and exchange of knowledge, as well as to the benefits agents can derive from their connection with a network. In economics, one of the most convincing approaches is represented by Arthur's model on increasing returns to adoption (Arthur, 1990). ${ }^{2}$ In a formal way, the models of increasing returns to adoption are based on the notion of network externalities. The payoffs agents may derive from their connection with a network are positively correlated with the number of previously connected agents. The basic idea is that the higher the number of connected agents, the higher the probability for an agent to communicate, to exchange or to capture strategic information in order to increase its satisfaction. This increasing satisfaction depends strongly on compatibility and complementarity criteria governing interactions and communication among connected agents. For Arthur, theses problems are essentially technological ones. However, we can easily show that these could also fall within the scope of knowledge dynamics. Agents tend to follow the adoption decision of others not only because of uncertainty or legitimacy, but also because of knowledge exchange and accessibility constraints. In a complex and systemic view of knowledge (Antonelli, 2006; Sorenson et al., 2006), firms will have a stronger chance of having access to external and complementary bits of knowledge stemming from cognitively distant firms if the number of firms connected with the knowledge network is high, thus reinforcing the attractiveness of the network as a whole (Vicente and Suire, 2007).

So, uncertainty, legitimacy, coordination and knowledge accessibility in networks are strong motives for mimetic interactions and can account for the emergence of collective behaviors. One of the most interesting extensions worth developing requires an investigation of the complex relations between the individual motives for imitation and the economic properties of collective behavior stability. ${ }^{3}$ The key criterion highlighting these relations, both in economics and in sociology, pertains to the nature of the payoff functions. For instance, in Arthur's model, as underlined by Geroski (2000), Orléan (2006) and Vicente and Suire (2007), the process of preferential imitation is based on an evolving payoff structure. Payoffs are an increasing function of the number of agents converging upon the same choice. Individual utility increases as the agents converge upon the same decision. The mimetic process which governs the emergence of collective behavior thus engenders a strong stability in time, as well as in space (the so-called path dependency). Conversely, when the informational effect plays a major role through uncertainty and legitimacy, the intrinsic utility of agents and their payoffs are not

2 Orléan (2006) alludes to 'preferential imitation' to qualify Arthur's model, thus establishing a clear difference with 'informational imitation' as developed in the model of Bikhchandani et al.

3 We define stability in a dynamic and evolutionary sense, i.e. stability in terms of performance and growth, and not within the scope of the neoclassical stability property, which is strongly associated with the notion of equilibrium (Boschma and Lambooy, 1999). 
affected by the behavior of others. We may even imagine that the convergence process in decision making can bring about negative externalities or self-defeating processes (Hedstrom, 1998), for instance when collective choices lead to congestion effects or to strong competing pressures. Thus, collective behavior resulting from an informational cascade is fragile. Bikhchandani et al. (1998) already identified these differentiated properties of stability when they observed that 'in many realistic settings, in addition to the informational externality described here, there are direct payoff interactions in a form of positive consumption of production externalities - sometimes called network externalities. The intuition here is that joining a network may help both the joiner and the others who have already joined. Uniformity is likely in the presence of network externalities. However, this uniformity does not display the fragility of an informational cascade' (p. 168).

\section{Cluster emergence and stability under decision externalities: two testable propositions}

All of the aforementioned general considerations lead to the following propositions concerning specifically clusters springing from the aggregative process of location decision-making.

Proposition 1: A cluster will be even more likely to emerge if the informational effect comes into play in the early stages of the location process. The weight of this effect will be even stronger if pioneer firms are perceived as fashion leaders by the others.

Again it is to be pointed out that the informational effect comes into play when uncertainty is strong. First, location decision-making can be imbued with strong uncertainty when firms are not characterized by high transportation costs and a clearly identified local labor force, so that there is no real place prevailing among the range of alternative locations they have at their disposal. This situation is typical of economic activities of the so-called weightless economy (Quah, 2000) where intangible production does not give rise to the same geographical constraints as economic activities producing tangible goods. Second, uncertainty can also prove strong when firms operate within emerging markets whose history is too short to provide sufficient information with a view to efficient individual location decision-making. Third, it can be strong when, in emerging high-tech sectors, the direction of technological development, the emerging technological standard and the identification of the main players are not well-defined (Nooteboom and Woolthuis, 2005). This situation is typical of the Internet industry and the start-up boom of the late nineties. Indeed, in the sector's structuring phase, there was strong uncertainty with respect to the emerging standard, demand, organizational practices, firm valuation, as well as in terms of location strategies. In such a context, firms, and their managers, are sensitive to signals derived from the location strategies of other firms they regard as undergoing similar economic constraints. As a matter of fact, cognitively close firms may enter into a locational cascade (Vicente and Suire, 2007) when they choose their location sequentially and follow predecessors they consider better informed. These mimetic behaviors, which are based on an observationallearning process (Manski, 2000), engender a kind of locational isomorphism (Appold, 2005) which may give rise to a cluster of firms, even if the first adopters' location choice merely proceeded from random decision-making. 
The colocation process is the aggregate result of neither geographical, nor technological constraints, but of individual decisions under social influence. This process is cumulative due to the increasing social pressure an area undergoes as the number of firms belonging to the same organizational field increases. The legitimacy of individual location decision-making is even stronger when the symbolical role of the emerging locational norm is strong. Within the framework of an empirical study on the French Silicon Sentier, Vicente et al. (2007) have underlined that, in spite of the nonexistence of technological relations among firms, the location's symbolical role had been instrumental in helping dotcom entrepreneurs to attract venture capital funds. The reason is that venture capitalists too experience uncertainty in terms of dotcoms' business model, and they infer that successful places certainly house more successful firms than others.

The probability of a locational cascade occurring in a given area rather than in another also depends on the first adopters' influence. The signal which the first adopters send will impact more the location decision-making of others if they are perceived as 'fashion leaders' in the organizational or industrial field. The less anonymous the first adopters are, the stronger is the geographical charisma of the place. The followers are thus convinced that to be located elsewhere could turn out to be a strategic error, so that a locational norm emerges rapidly, which sometimes comes as a surprise for the policy makers and local elites concerned. Again, some stylized facts seem to back up this proposition. In the case of the Silicon Sentier for instance, the location of Yahoo.fr (1997), followed closely by Lycos.fr and Nomade.fr in 1998, ${ }^{4}$ had generated a locational cascade (or bubble) with the establishment of some 300 more or less anonymous dotcoms up to 2000 . The Silicon Sentier thus became rapidly the locational norm for French dotcoms. This self-organized phenomenon had been favored by the media, which would not have been the case if the first adopters had not been (or supposed to be) the most successful dotcoms at the time. Locational cascades can also be 'pushed' by local elites. By way of example, in the late seventies, the instigators of the Sophia Antipolis research park had pointed to the location of IBM and Texas Instruments plants, within the framework of the project's marketing strategy, with a view to attracting other plants of computer and telecommunications big companies (Longhi, 1999).

Proposition 2: A cluster will exhibit stronger stability if the network effect prevails over the informational effect in the colocation process. The level of cognitive distance is the associated critical parameter of the clusters' stability properties.

Uncertainty decrease and the search for legitimacy could provide interesting explanations on the reasons why clusters emerge as locational norms. Nevertheless, the geographical charisma of clusters - the fact that some high-tech places are in fashion - is not a guarantee of long-term success and aggregate performance. This proposition can partly be justified by the evolving payoff properties governing the convergence process of location decision-making. The intrinsic stability of clusters will depend on the balance between the firms' individual motives for establishing themselves

4 Note that these three companies are cognitively close - three Internet portal companies - which confirms the argument according to which colocation processes under uncertainty and legitimacy lead to a low level of cognitive distance. 
close to others. When uncertainty prevails over knowledge sharing within networks, firms converge rapidly upon the same site and may thus gain legitimacy in the short term. But the collective pattern is fragile, especially on account of the nonevolving payoff structure as mentioned above. Conversely, when network effects prevail over informational or signaling effects, the colocation of firms is the result of a sequential process in which firms compare the benefits of each place according to their own preferences, as well as according to the predecessors' location which they consider relevant in terms of knowledge production function.

In the peculiar case of clustering processes, how can we explain the differentiated evolution of the payoff structure between clusters emerging from locational cascades and clusters in which knowledge networks prevail? The level of cognitive distance between firms provides some convincing explanations in this regard. Again it is to be pointed out that the level of cognitive distance is related to the firms' motives for establishing themselves close to others. Uncertainty and legitimacy can imply a low level of cognitive distance insofar as the signaling effect functions mainly among firms with close industrial or market - and so knowledge - characteristics. This argument is consistent with the definition of an organizational field as developed in Di Maggio and Powell's explanation of mimetic isomorphism. Firms are only inclined to emulate those which they regard as facing the same market and knowledge constraints, and so the same problems in terms of location decision-making. If the location aggregation process retroacts positively on each firm's individual legitimacy, it also increases the risks of unintended knowledge spillovers (Boschma, 2005), thus bringing about knowledge appropriation defaults (Brossard and Vicente, 2007). So it appears that, against the trend of the literature, clustering processes based on these individual motives may give rise to a climate of mistrust and suspicion due to too strong a cognitive proximity between firms. Knowledge outflows are more risky if geographically close firms are cognitively close so that they exhibit similar absorptive capabilities (Nooteboon, 2000). This climate of suspicion may consequently engender cluster instability. On the other hand, when clustering processes are dominated by the firms' motives for having access to external pieces of complementary knowledge, the level of cognitive distance is higher than in the previous case (i.e. the case where clusters arise from locational cascades). In a complex and systemic view of knowledge (Antonelli, 2005; Sorenson et al., 2006), firms establish their innovation strategies by combining internal and external knowledge within networks. When choosing their location, they need to take into consideration their motives for both maintaining sufficient internal knowledge appropriability and facilitating external knowledge accessibility. So, clusters may emerge with a certain amount of cognitive distance when firms value knowledge accessibility over knowledge appropriability, and locate close to others with a view to finding partners in technological fields where knowledge is fragmented into many technological areas. Geographical proximity is needed in these situations due to the difference in absorptive capabilities between the various partners concerned, which calls for frequent meetings and engineers' mobility in order to favor mutual understanding (Nooteboon, 2000) and the diffusion of tacit knowledge through social networks. Relational thickness is therefore stronger in clusters where knowledge networks prevail than in clusters based on locational cascades. Relations are facilitated by the fact that firms do not originally compete in the same markets, and so the risks of unintended knowledge outflows are lower than in the previous case. Trust thus emerges more easily 
and insures a higher dynamic stability for clusters based on knowledge networks than for clusters based on locational cascades.

Empirical evidence seems to back up such a proposition. When uncertainty and legitimacy through the informational effect prevail in the emergence of clusters, collective efficiency is far from being proved. In the case of US science parks, Appold (2005) reveals that clusters can emerge without functional interdependences among firms, and he further mentions that the cumulative location process, in spite of the geographical charisma, does not necessarily enhance collective and organizational efficiency. Dalla Pria and Vicente (2005) and Vicente and Suire (2007) emphasize that the sudden decline of the fashionable French Silicon Sentier was partly due to an excess of competition and the resulting nonexistence of knowledge relations among cognitively close firms. The climate of suspicion and the risks of unintended knowledge outflows were particularly perceptible when entrepreneurs acknowledged that they did not want to send their employees to represent their start-up at First Tuesday meetings ${ }^{5}$ on account of their being courted by other start-ups. The relocation of Yahoo.fr in 2000, during the Internet bubble's crash, quickly resulted in a cascade of relocations until the Silicon Sentier became the Silicon desert. ${ }^{6}$ Another interesting case is that concerning the French cluster of Sophia Antipolis (Longhi, 1999), which chronologically displays the two aforementioned effects. First, the intensive international marketing policy promoting the site and the initial locations of IBM and Texas Instruments plants generated a strong mimetic locational isomorphism close to the one identified by Appold in the US. After this period of growth, the cluster entered into a phase of stagnation in the early nineties due to the nonexistence of knowledge relations. Nevertheless, benefiting from a critical mass of firms located in the area, local policy makers, who were conscious that geographical proximity is not sufficient to generate collective value added, then proceeded to favor network relations among firms stemming from the software, hardware and telecommunications industry. The technological complementarities between these firms thus led to the emergence of the so-called Telecom Valley, which appears nowadays as a famous and attractive European place dedicated to secure communications technologies (Longhi et al., 2004).

These two simple propositions open up perspectives which allow us to enter differently from the major part of the literature into the black box of local knowledge spillovers. They emphasize the fact that location decision externalities precede local knowledge spillovers, so that the latter can have ambivalent effects on the stability and aggregate performance of clusters. They highlight de facto the critical parameters of cluster dynamics: (i) the firms' motives and incentives for convergence upon location decision-making and the resulting level of cognitive distance between colocated firms,

5 An informal networking forum intended for technology entrepreneurs, companies seeking venture capital and investors.

6 Dalla Pria and Vicente (2006) have identified the reasons for the rapid success and then the sudden decline of the Silicon Sentier through a sociological approach based on a series of 70 semi-structured interviews. They have shown that the bankruptcy of some firms only explains a small part of this decline. According to us the departure of Yahoo.fr sent a negative signal to the firms that remained - i.e. those that survived the Internet bubble crash. As a result, these firms decided to relocate their activities in other areas of Paris. Six months after the bubble crash the very entrepreneurs who had previously promoted the cluster were declaring: 'There was no Silicon Sentier religion for me. It's just convenient and cheap, but it has given its members a bad image', 'The Silicon Sentier is now the silicon desert', or 'Today, this place symbolizes the start up chaos and the excesses of the new economy (1990s)' (Dalla Pria and Vicente, 2006). 
and (ii) the role of 'fashion leaders', or more generally firms that can exert a strong influence on the location decision-making of others.

These are key parameters in that they allow us to understand cluster formation and stability. The following sections put forward a simulation-based model which includes these parameters and tests these propositions by associating clusters with locational norms. Simulation-based models are particularly well suited as they provide useful results that capture the evolutionary pathways we have identified in the aforementioned case studies. They make it possible to discuss the relations between the individual parameters of location decision-making and the resulting collective structures. These relations should prove useful in conducting, in an evolutionary framework, more systematic empirical studies on clusters.

\section{A simple model of locational norm stability}

In the tradition of sociology (Granovetter, 1978; Schelling, 1978; Hedstrom, 1998) and economics (Orléan, 2006), the purpose of this section is to model individual binary decision under social influence constraint. In line with Lopez-Pintado and Watts (2008), it is clear that, as addressed above, location decision-making can be interpreted in terms of different motivations. In order to propose a general norm location dynamics modeling framework, we first need to categorize the origin of decision externalities. To that end, we distinguish between two types of decisions:

(i) Decisions taken within the scope of a search for strategic complementarity, arising when a firm's utility over a particular location is a positive function of the number of other firms choosing this alternative (the network externality effect);

(ii) Decisions taken within the scope of a search for legitimacy, arising as a result of inferences which firms draw from information regarding the decisions reached by other firms [the informational (or reputational) effect].

As Lopez-Pintado and Watts (2008) have underlined, these two types of externalities cannot, most of the time, be derived from a unified framework. Nevertheless, our following proposal tries to capture both mechanisms of social influence through the use of an influence response function.

To formalize our approach clearly, we put forward a conditional decision-making model in line with Granovetter (1978). We assume that any given firm $i \in N$ has to make a norm location choice $\left(d_{i}\right)$ conditional upon the decisions of one or more other firms $\left(d_{j}\right)$ with $j \in N \backslash\{i\}$. In view of a decision which can be described in two dimensions, ${ }^{7}$ i.e. $D=\{0,1\}$ and $d_{i} \in D$, a conditional decision model posits:

$$
\operatorname{Pr}\left(d_{i}=1\right)=f\left(d_{j}\right)
$$

Thus, if each decision is viewed as a sequential and discrete point in time, the decision of firm $i$ at time $t$ depends at least partly on the decision of firms $j$ at time $t-1$. As underlined by Watts (2006), both Schelling (1978) and Granovetter (1978) have

7 It is to be noted that extending our model so that it is based on a wider range of strategies does not modify our qualitative results. 
argued that a binary decision framework may be much more general partly on account of the fact that (i) many decisions are binary by nature, and (ii) more multifaceted decisions can effectively be reduced to binary decisions: on the one hand, conforming to the majority norm versus choosing one among many possible alternatives and, on the other hand, locating in the emergent or dominant cluster versus opting for an alternative location. For the purposes of our analysis, as well as for reasons of tractability, we retain two norm location choices.

For any firm $i \neq j$, let $\bar{d}_{j \neq i}=\left(d_{1}, \ldots, d_{i-1}, d_{i+1}, \ldots, d_{n}\right) \in D^{N-1}$ be the action profile representing the behavior of the remaining firms in the population. We define a function $P_{i}: D^{N-1} \rightarrow[0,1]$ so that $P_{i}\left(\bar{d}_{j \neq i}\right)$ is firm $i$ 's probability of choosing the 1-norm location given the strategies $\bar{d}_{j \neq i}$ of the remaining firms, with $P_{i}\left(\bar{d}_{j \neq i}\right) \in[0,1]$ in case of continuous probability.

We introduce a relevant neighbor principle (or interaction neighborhood) in order to model the limited rationality of firms (David, 1988; Kirman, 1997). Indeed, except for some emergent territories where there are very few firms established, many clusters are more or less dense. Thus, it is reasonable to assume that new entrants cannot rebuild the historical sequence of discrete location due to a lack of cognitive capacity, or simply due to the fact that this public information is not available. To put it differently, this relevant neighbor principle is viewed as one of the idiosyncratic characteristics of firm $i$. Following Watts (2006), we then consider a function $p_{i}$ denoted as the influence response function, so that:

$$
P_{i}\left(\bar{d}_{j \neq i}\right)=p_{i}\left(k_{i}\left(\bar{d}_{j \neq i}\right)\right) \in[0,1]
$$

where $k_{i}$ is the level of decision externalities or social signal in the words of Watts (2006). This neighborhood influence on firm $i$ 's decision is defined as follows:

$$
k_{i}\left(\bar{d}_{j \neq i}\right)=\sum_{j \in N \backslash\{i\}} d_{j}
$$

Firms are located within a two-dimension graph interaction ${ }^{8}$ and we consider a von Neumann neighborhood in such a way that the decision of any firm $i$ is conditional upon the decision of the four nearest neighbors. As a consequence, the social signal level can only be $k_{i}\left(\bar{d}_{j \neq i}\right) \in[0,1,2,3,4]$. Thus, each firm can benefit from a signal, a decision externality that may vary from 0 to 4 . In a case where the influence structure is supposed to be undirected and unweighted, previous specifications simply mean that the probability of choosing the 1-norm location is dependent upon the number of firms choosing the 1-norm location in the neighborhood. In the presence of positive externalities, the more strategy 1 is adopted within the neighborhood, the higher the probability is for a firm $i$ to switch to strategy 1.

Finally, we assume that any firm $i \in N$ is characterized by a utility function $u_{i}\left(d_{i}, k_{i}\right)$ so that both the social influence and private strategy of firm $i$ are arguments of the payoff function. If we note $\Delta U=u_{i}\left(1, k_{i}\right)-u_{i}\left(0, k_{i}\right)$, a rational firm $i$ will choose the 1-norm location if $\Delta U>0$ and keep its initial strategy otherwise. 


\subsection{An influence response function as a stochastic process}

The previous function determines the aggregate behavior of firms. Different equilibriums can be computed according to this function's critical parameters.

In what follows, we propose to consider a stochastic influence response function. There are many reasons why firms behave stochastically. We may, for instance, refer to uncertainty as to the ex post value of the $d$-norm location, the signal or the characteristics of other players. But, as mentioned above, the reason we could also put forward is the sector's immaturity and the resulting lack of industrial standard. Formally, the utility associated with strategy 1 for a firm $i$ is then $u_{i}\left(1, k_{i}\right)=\varphi_{1}\left(k_{i}\right)+\varepsilon_{1}$ where $\varphi_{1}($.$) is supposed to be increasing with respect to k_{i}$ and is then related to peer pressure effect or social influence level. $\varepsilon_{1}$ is a random term. Symmetrically, the utility associated with the 0 -norm location for a firm $i$ is $u_{i}\left(0, k_{i}\right)=\varphi_{0}\left(k_{i}\right)+\varepsilon_{0}$ whereas $\varphi_{0}($. decreases with respect to $k_{i}$.

Following our above considerations:

$$
\begin{aligned}
& \Delta U>0 \Leftrightarrow u_{i}\left(1, k_{i}\right)-u_{i}\left(0, k_{i}\right)>0 \\
& \Leftrightarrow \varphi_{1}\left(k_{i}\right)+\varepsilon_{1}-\varphi_{0}\left(k_{i}\right)-\varepsilon_{0}>0 \\
& \Leftrightarrow\left(\varphi_{1}\left(k_{i}\right)-\varphi_{0}\left(k_{i}\right)\right)+\left(\varepsilon_{1}-\varepsilon_{0}\right)>0 \\
& \Leftrightarrow\left(\theta_{1}\left(k_{i}\right)-\theta_{0}\left(k_{i}\right)\right)>0 \\
& \text { with } \theta_{1}\left(k_{i}\right)=\varphi_{1}\left(k_{i}\right)+\varepsilon_{1} \text { and } \theta_{0}\left(k_{i}\right)=\varphi_{0}\left(k_{i}\right)+\varepsilon_{0}
\end{aligned}
$$

The individual decision depends on the difference of both social signals and the specific forms of the functions $\theta_{1}\left(k_{i}\right)$ and $\theta_{0}\left(k_{i}\right)$. Finally, previous $p_{i}\left(k_{i}\right)$ is formally defined as:

$$
p_{i}\left(k_{i}\right)=\left(\theta_{1}\left(k_{i}\right)-\theta_{0}\left(k_{i}\right)\right)
$$

To illustrate this mechanism, we propose polar deterministic cases in which $p_{i}\left(k_{i}\right)$ is the probability of firm $i$ 's adopting the 1 -norm location when exactly $k$ firms within the neighborhood adopt this strategy. ${ }^{9}$ The positive externalities simply mean that the higher the overall number of adopters of the 1-norm location, the higher the probability of adopting the 1-norm location.

Case 1: a linear increasing probability means that the probability of firm $i$ 's adopting the 1-norm location increases monotically as the strategy spreads in the neighborhood. In that case, the cluster will develop linearly with the number of firms within a specific sector (Figure 1).

A more convincing specification consists in considering a threshold model à la Granovetter (1978). Thus, before adopting a given dominant strategy, firms may 'wait' for a more or less long time until it spreads within the neighborhood. Many documented situations can be interpreted in that way. Among others, we may quote Granovetter's well-known model (1978) on collective rioting, the informational cascades of Bikhchandani et al., or Hedstrom's (1998) rational imitation model. Concerning clusters, we may argue that an emerging sector and an

9 In this article, we only considered the case of positive externalities. There obviously are many situations where territories are characterized by negative externalities or diseconomies of agglomeration resulting from congestion effects. This case will be the subject of further work later on. 


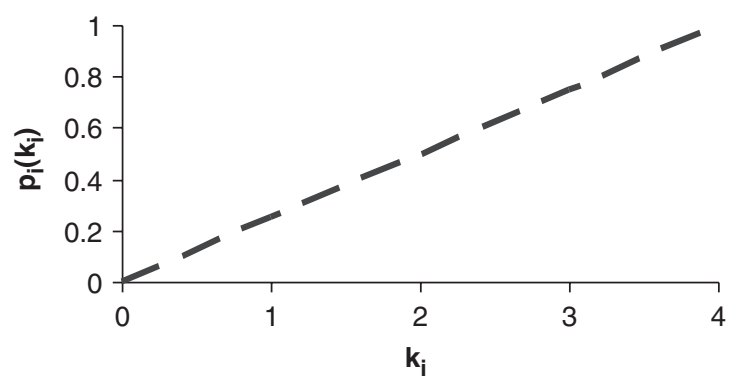

Figure 1. Conditional and linear behavior.

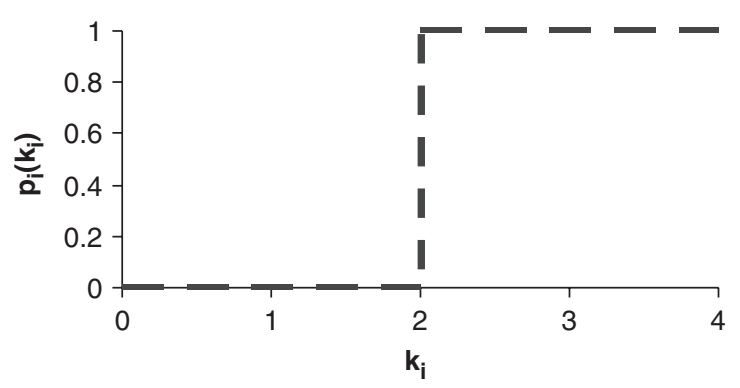

Figure 2. Conditional and threshold behavior.

unstable knowledge base, as well as unidentified leading players, can give rise to such a behavior.

Case 2: a threshold behavior means that below an alternative strategy's diffusion threshold $\left(k_{i}^{T}\right)$, firm $i$ does not adopt the 1-norm location. Strategy 1 is then chosen if $k_{i} \geq k_{i}^{T}$.

The following figure represents a case where $k_{i}^{T}=2$ means that below $50 \%$, firm $i$ does not switch to the 1-norm location: $p_{i}\left(k_{i}\right)=0$. Conversely, we logically get $p_{i}\left(k_{i}\right)=1$ as soon as two firms adopt the 1-norm location strategy (Figure 2).

Finally, as has been mentioned above, we address the question of a more generalized behavior through a stochastic influence response function in order to capture better what should be the life cycle of a cluster (Menzel and Fornahl, 2007; Ter Wal and Boshma, 2007). To that end, we impose only two conditions upon $p_{i}\left(k_{i}\right)$ :

Assumption 1: $\left.p_{i}\left(k_{i}\right) \in\right] 0,1[$

Assumption 2: $p_{i}(0)<p_{i}(1)<p_{i}(2)<p_{i}(3)<p_{i}(4)$ in order to respect a principle of cumulative interaction and the idea that the higher the number of firms' choosing the 1-norm location in the neighborhood, the higher the probability of choosing this strategy.

Finally, as our model is symmetric, we also have $\left\{\begin{array}{l}p_{i}(3)=1-p_{1}(1) \\ p_{i}(4)=1-p_{i}(0)\end{array}\right.$ and, as a consequence, we are left with three critical parameters $\left\{p_{i}(0), p_{i}(1), p_{i}(2)\right\}$ which we can use to qualify stochastic behavior and specify the influence response function. 


\subsection{Decision externalities under uncertainty and reputational effect}

Following previous works on informational cascades for instance (Banerjee, 1992; Bikhchandani et al., 1998), agents tend to forget their private signal about a strategy as soon as the information-concerning actions taken by other firms in the population is used by them to reduce uncertainty and infer optimal choice. When firms fail to distinguish between alternative locational returns, the number of firms located in a territory may be perceived as a signal of the 'quality' or 'geographical charisma' of the place. Signals are regarded as 'activities or attributes of individuals [...] which by design or accident, alter the beliefs of, or convey information to, other individuals' (Spence, 1974). As reminded by Appold (2005), 'institutional theory suggests that the action of similar firms that have faced the same situation in the past provides credible behavioral clues in the absence of direct information'. The presence of similar firms may serve as a 'filter' to distinguish between good and bad choice options. Indeed, the presence of successful similar firms located at a particular site could be a good indicator of the place's collective performance, without it being necessarily possible to understand why. As has previously been suggested, these places are characterized by a strong cognitive proximity. Following these considerations, we propose to compute the influence of response function in a particular way with a view to simulating the collective outcome of this decision process.

When a firm is faced with both strategies under uncertainty, a rational choice is a random draw between the two. We model this proposition considering that for a typical firm $i, p_{i}(2)=0.5$ means that when both strategies are equally adopted in the neighborhood, the probability of choosing the 1-norm location is then 0.5 . However, it is important to introduce two more parameters in order to describe the profile action under uncertainty. On the one hand, we consider that some firms may have more legitimacy (real or supposed to be real) than others. In that case, when a firm $i$ is confronted with a 'fashion leader', it weights the fashion leader's signal with a probability $p_{i}(1)$. Under Assumption 2, the higher this probability is, the more the 'fashion leader' is weighted within the neighborhood. On the other hand, if we imagine a stable collective belief system where each firm adopts the 0-norm location, an unconditional behavior with a nonnull probability is necessary in order to start the colocation process $p_{i}(0)>0$. To sum up, $\left\{p_{i}(0), p_{i}(1)\right\}$ models both the probability of a pioneer's behavior ${ }^{10}$ as well as this pioneer's credibility through the influence of its behavior on the decision of followers.

Our simulation protocol is strictly similar to Schelling's (1971). The dynamics of collective diffusion is obtained by drawing, at each time step, one firm from a population sized $N=2500$ whose adoption probability, as a function of its neighborhood, is then denoted as $p_{i}\left(k_{i}\right)$. This stochastic interaction model is a sequential and cumulative action model (Cox and Durrett, 1991).

Different conjectures emerge from our different simulations, which could be connected with the empirical observation. On the one hand, when cognitive proximity is high but the fashion leader's legitimacy is rather low, the 1-norm location never

10 We could as well consider the case of a firm being responsible for the creation of a disruptive innovation for instance. 


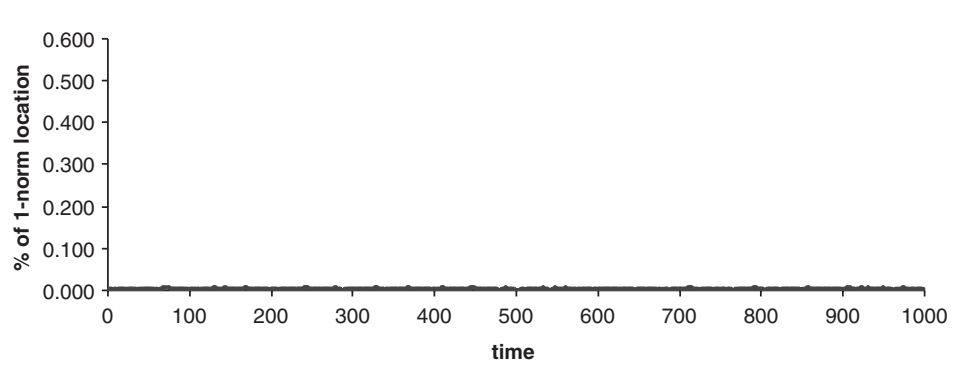

Figure 3. Few first pioneers with low contagion.

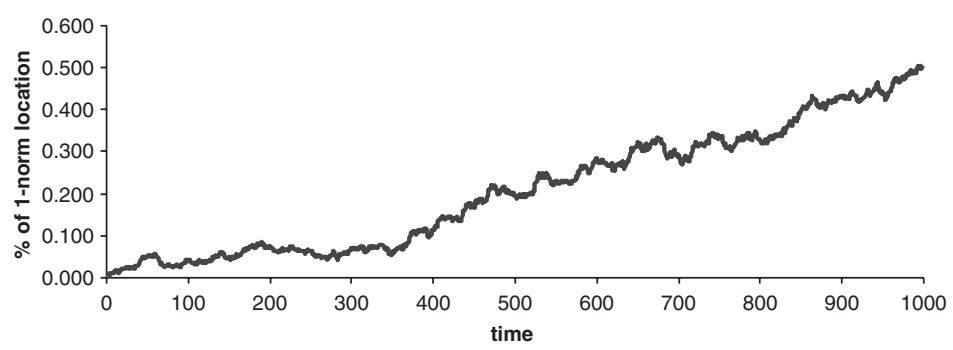

Figure 4. Few first pioneers with low contagion.

becomes a dominant strategy within the population (Figure 3). We model this conjecture with the following parameters over $t=1000$ period:

$$
\left\{p_{i}(0) ; p_{i}(1) ; p_{i}(2)\right\}=\{0.002 ; 0.04 ; 0.5\}
$$

In that case, the 1-norm location never spreads through the population. Indeed, under uncertainty, firms do not consider getting higher utility by 'following' a fashion leader whose legitimacy is rather low. In short, the signal's credibility is not sufficient to counterbalance the strategy adopted by firms, and these do not anticipate significant benefits from such a switch, so that: $\Delta U \leq 0$.

On the other hand, if this legitimacy becomes more important, the fashion leader comes to be more weighted in the neighborhood, and the 1-norm location becomes a plausible alternative, except when uncertainty prevails. In the event of an informational cascade, indeed, stability is not assured and the collective outcome is unstable (Figure 4). This influence response function captures such a scenario with:

$$
\left\{p_{i}(0) ; p_{i}(1) ; p_{i}(2)\right\}=\{0.002 ; 0.15 ; 0.5\}
$$

We find close results when increasing pioneer's behavior $p_{i}(0)$ with the two following 'fashion leader' effects weighted differently (Figures 5 and 6):

$$
\left\{p_{i}(0) ; p_{i}(1) ; p_{i}(2)\right\}=\{0.11 ; 0.15 ; 0.5\}
$$

and:

$$
\left\{p_{i}(0) ; p_{i}(1) ; p_{i}(2)\right\}=\{0.11 ; 0.26 ; 0.5\}
$$




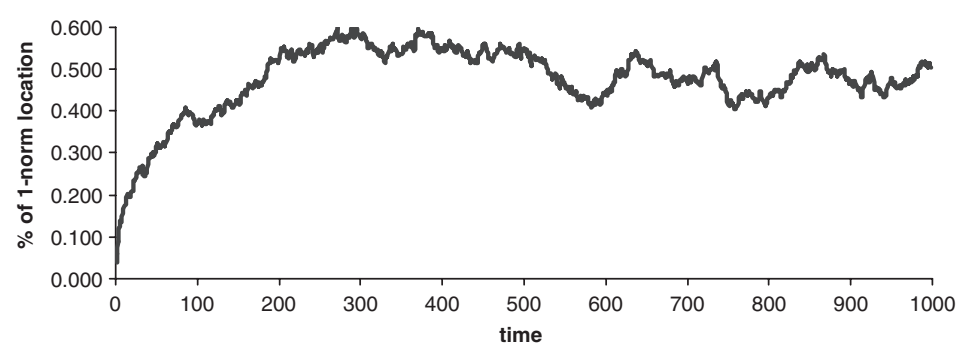

Figure 5. Numerous pioneers with low contagion.

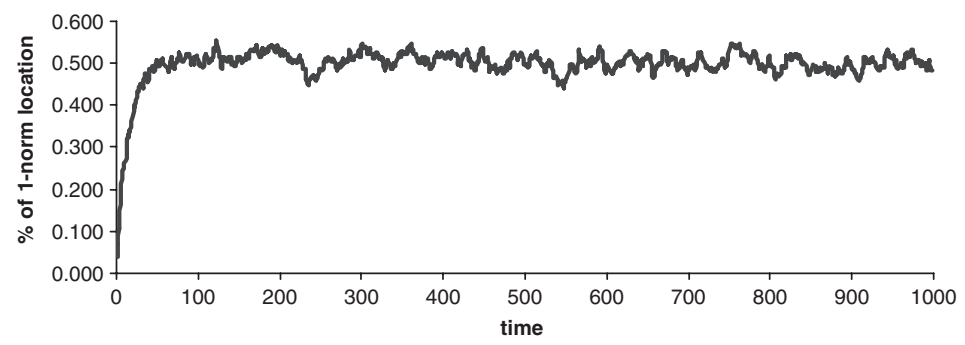

Figure 6. Numerous pioneers with high contagion.

Furthermore, it could be interesting to confront the respective weight of fashion leader and legitimacy effects and capture threshold effects on the norm-location dynamics. The following figure (Figure 7) proposes for each couple of $(p(0), p(1))^{11}$ the mean proportion of firms adopting 1-norm location. There is a discontinuity between what it appears to be two different regimes. For some rather low values of $p(0)$ and $p(1)$, i.e a regime in which fashion leader effects as well as pioneer behaviors are rare, the system remains lock into the 0 -norm location. On contrary, as soon as disruptive behaviors appear $[p(0)$ increases] and these behaviors appear to be credible for the population $[p(1)$ increases], the system passes through a brutal phase transition and converges to a state where both norms coexist.

In addition, the phase transition does not appear for the same values of $p(0)$ and $p(1)$ meaning that there would exist a relationship between these two critical parameters (Figure 8). In order to lock-out the dominant norm location, both behaviors are necessary. But it appears graphically that $p(0)$ is more important that $p(1)$ to start the phase transition. For a low $p(0)$ one need a high $p(1)$ whereas the phase transition occurs quicker for a couple of high $p(0)$ whatever the value of $p(1)$. That means that disruptive or pioneer behaviors are more important than fashion leader effects in order to start the phase transition.

During the development of a technological field, which is characterized by a high level of uncertainty, the principles of informational legitimacy and contagion are central

11 We restrict to some value for $p(0)$ and $p(1)$ inferior to 0.25 as results for higher values do not provide more information. 


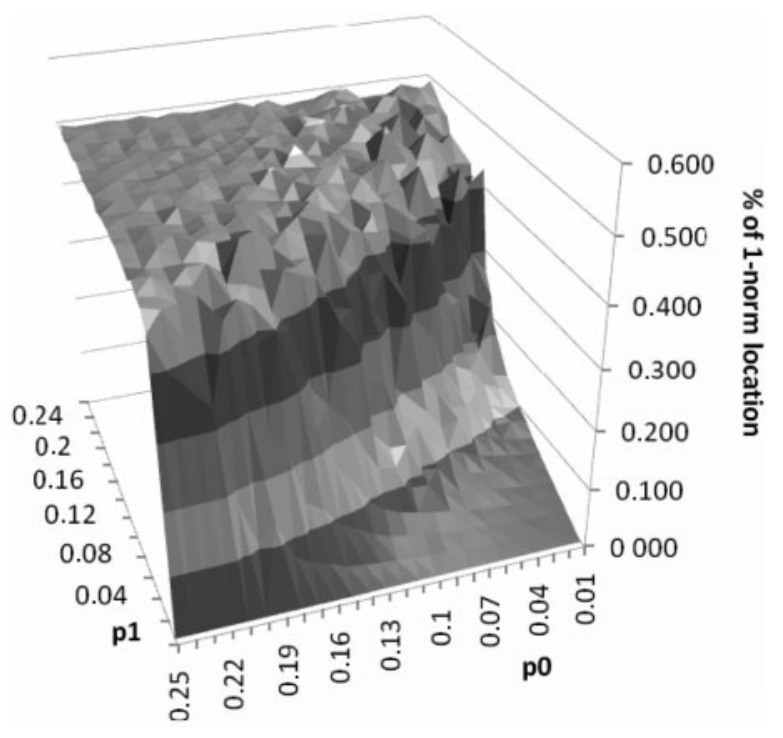

Figure 7. Phase transition.

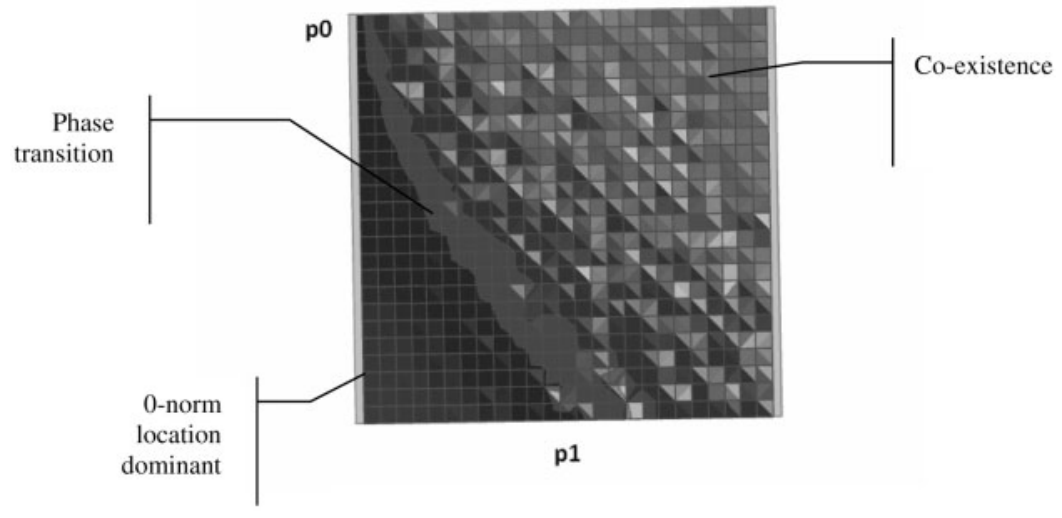

Figure 8. Diffusion of norm location.

mechanisms that determine the convergence toward a technological norm. The simulation results exhibit different interesting patterns. First, we observe that location norm 1 never spreads across the population for an important range of values for $p(0)$ and $p(1)$. This is typical of mature clusters in which individual disruptive behaviors are very rare. But as soon as the probability of pioneer or disruptive behavior occurring increases, and when this type of behavior is considered legitimate by the other firms, then the system enters into an unstable phase transition regime. If the benefits derived from the disruptive behavior or the associated technological innovation do not exist, then the firms revise their choices and the probability of this behavior occurring decreases and the system returns to the state where location norm 0 is dominant. In the same way, the dynamic is the same if legitimacy decreases during the transitory regime. Finally, a legitimacy-based mimetic process can cause a rapid change in the location 
norm when the pioneers' reputation remains strong. But location norm 1 can, at best, coexist with the previous one, but does not spread across the population. But the system can get 'stuck' in this state because the excessive cognitive proximity between firms and the homophilic behavior they foster generates a level of distrust that hinders openness and creative knowledge exchanges (Fleming and Marx, 2006; Nooteboom, 2006). As far as we know, many clusters can be affected by this type of situation where uncertainty and strong cognitive proximity prevent collective innovation and undermine cluster growth (Longhi, 1999; Appold, 2005; Vicente and Suire, 2007). To put it differently, the absence of a well-established standard, on the basis of which firms may benefit mutually from their colocation, can lead to these forms of clustering process. Clusters need to generate network externalities in order to become a new location standard.

\subsection{Decision externalities under strategic complementarities and cognitive distance}

Up to now, we have only examined the case of uncertainty situations and the resulting informational and reputational effect. We have highlighted the typical collective outcome that may emerge from these individual decisions. Now, it is to be pointed out again that many clusters arise as well out of firms' search for accessibility to the knowledge base, technological complementarities and technological convergence. The idea is that 'efficient clusters' are clusters exhibiting a related variety (Boschma and Iammarino, 2007; Frenken et al., 2007). From an individual point of view, the utility assigned to a firm depends explicitly on the relative number of firms choosing the 1-norm location. The technology adoption model of Katz and Shapiro (1985), which rests on the role played by positive network externalities, basically is a good example of decision externalities with strategic complementarities. Clusters exhibiting this collective property are Silicon Valley-type clusters where the colocation process is dominated by the search for complementary activities, the sharing of nonredundant knowledge, or the access to a knowledge base growing with the number of firms located within the cluster. The collective outcomes are radically different in this case. The following simulations address this issue.

In order to take into account the possibility of increasing returns through the adoption of the 1-norm location strategy, we have to set influence response function $p_{i}(2)$ at a level strictly superior to $1 / 2$. This situation means that when both strategies are equally adopted within a neighborhood, firm $i$ will switch to the 1-norm location strategy with a greater than $1 / 2$ probability. Then, $p_{i}(2)>1 / 2$ captures the idea that, when the network effect associated with the benefits firms can gain from their complementary neighbors is stronger in the alternative location, firms are not indifferent any more to both of the locational alternatives when these are equally distributed in their neighborhood.

We consider a first case where the cluster resulting from adoption of the 1-norm location exhibits two main characteristics. The first is about the rather low agglomeration speed, while the second relates to a weak fashion leader effect. Note that these two elements are often correlated in the case of clusters where the process of open technological collaboration needs a long time to occur, especially if gatekeeper firms are absent (Fleming and Marx 2006) or mistrust highly present. Along the same lines, the weakness of technological interdependence can be the consequence of too 


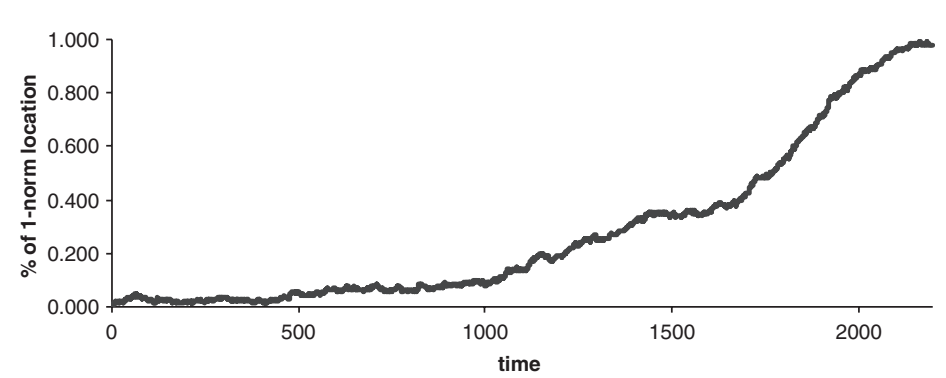

Figure 9. Clustering dynamics with weak network effect.

strong cognitive proximity (Figure 9). The following influence response function captures this scenario over $t=2200$ period:

$$
\left\{p_{i}(0) ; p_{i}(1) ; p_{i}(2)\right\}=\{0.002 ; 0.11 ; 0.55\}
$$

This situation is typical of clusters where individual utility does not increase quickly with collective adoption. Nevertheless, the collective outcome appears to be highly stable. Industrial sectors where technology is not mature, or collaborative research and development are supported by a nonoptimal cognitive distance (Nooteboom et al., 2005) can be illustrative of such a low process. But, contrary to the former case, a standard of location arises at some point in time with the emergence of a critical mass of firms at sufficient cognitive distance.

The two following figures (Figures 10 and 11) are obtained by increasing gradually the weight of the network effect:

$$
\left\{p_{i}(0) ; p_{i}(1) ; p_{i}(2)\right\}=\{0.002 ; 0.11 ; 0.6\}
$$

and:

$$
\left\{p_{i}(0) ; p_{i}(1) ; p_{i}(2)\right\}=\{0.002 ; 0.11 ; 0.7\}
$$

Beyond any doubt, the stability of emerging clusters is once again confirmed, and the speed of the contagion process increases as the network effect increases. ${ }^{12}$ The following figure (Figure 12) is the spatial diffusion process with $\left\{p_{i}(0) ; p_{i}(1) ; p_{i}(2)\right\}=\{0.002 ; 0.11 ; 0.6\}$ few firms innovate by adopting a disruptive behavior. A technological field emerges thanks to the aggregation of various bricks of knowledge. In the process of diffusion of a location norm, some firms appear to play a crucial role; they find themselves, at a moment in time, at the intersection of two technologies and their decisions will determine the transition toward a new norm. The higher the legitimacy of these gatekeeper firms, the higher the individual probability to switch to a more profitable technological process. Thus, some technological cliques are a necessary condition for the emergence of a sigmoid diffusion process. The growths of cliques lead to a critical mass of firms adopting location norm 1 and characterize the tipping point on the sigmoid trajectory. Obviously, the critical mass is highly dependant

12 The increasing values of $p(0)$ and $p(1)$ display, as in the previous simulations, the speed of the convergence process, without there being any consequence on the stability of the aggregate structure. 


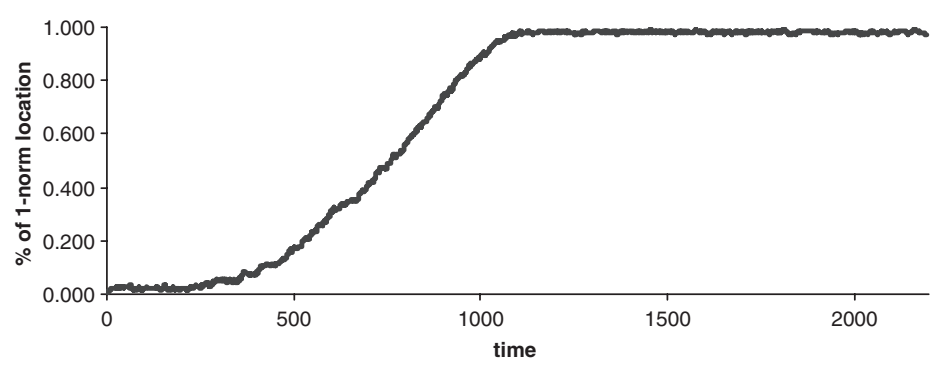

Figure 10. Clustering dynamics with intermediate network effect.

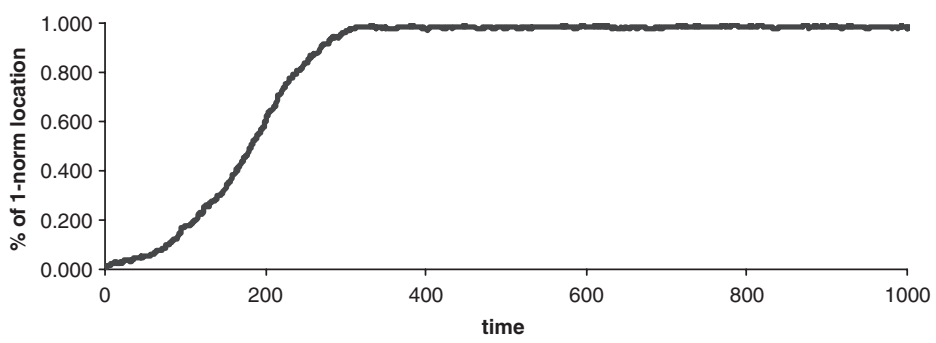

Figure 11. Clustering dynamics with strong network effect.

on the size of the population and the interaction structure between firms. If some pioneer behavior is a necessary condition for the emergence of a new location norm, the existence of a structure of interaction between the firms explains the emergence of knowledge cliques; and then the structuration through aggregation occurs thanks to the key role played by the gatekeeper firms.

Consequently, an emerging cluster is highly attractive as a result of the increasing payoffs firms gain from better knowledge accessibility and technological crossabsorption. The stability of the locational standard can then be correlated with the growing diffusion of a standard within a technological field (Aoki and Takizawa, 2002). Indeed, in technological fields where firms face constraints of compatibility, interoperability and modularity among many fragmented pieces of internal and external knowledge, the process of tacit knowledge exchange requires mutual understanding, as well as additional $\mathrm{R} \& \mathrm{D}$ phases with a view to technological integration examination (Brossard and Vicente, 2007). It therefore being risky and inefficient for firms to locate away from others. This result is consistent with the main explanation that Saxenian (1994) provided concerning the reasons for the continuous growth of the Silicon Valley over more than half a century: 'Silicon Valley is a regional network-based industrial system that promotes collective learning and flexible adjustment among specialist producers of a complex of related technologies.'

\section{Synthesis and concluding remarks}

In this article, we started by setting out that location decision externalities precede local knowledge spillovers in the explanation of cluster aggregate efficiency. Behind this postulate, we mean that the firms' individual motives for locating in the neighborhood 

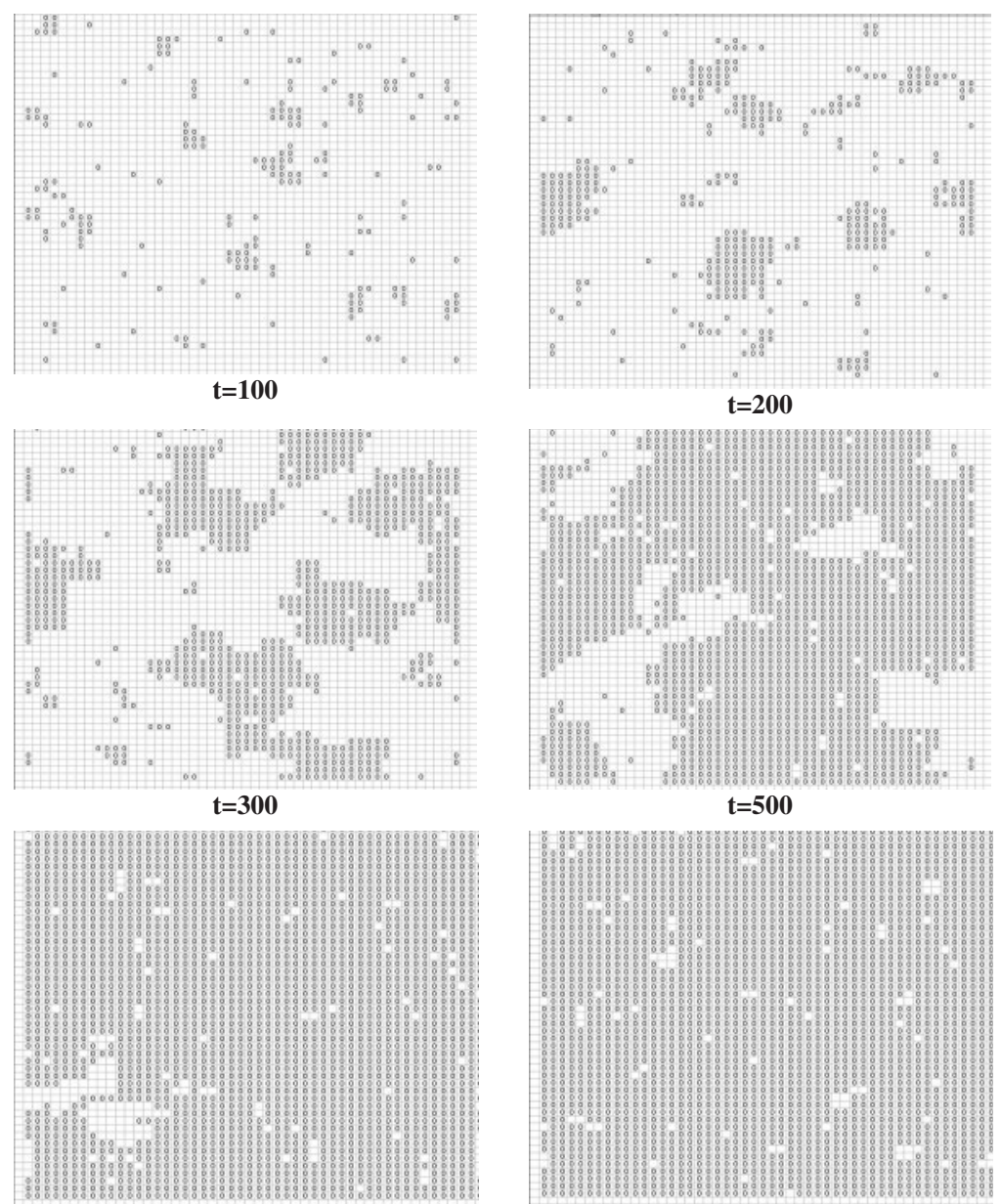

$\mathbf{t}>\mathbf{1 0 0 0}$

Figure 12. Spatial diffusion of norm location.

of others invariably generate knowledge spillovers which, according to the nature of these motives, may have ambivalent effects on the stability and performance of clusters. We have identified two main motives for firms to enter into a herding locational behavior: uncertainty and legitimacy on the one hand, and network and knowledge accessibility on the other hand, each one of these effects implying a distinctive amount of cognitive distance between firms. Two propositions have been put forward and tested in order to study the clustering process under location decision externalities and capture these ambivalent effects.

Our two general propositions seem to be validated by our simulation results. First of all, the model confirms Proposition 1 according to which the weight of the informational and legitimacy effects strongly influences the speed of the clustering process. This is consistent with the main stylized facts on clusters' (short or long) success stories. Clusters gain a sort of symbolical capital from the location of some other reputed and well-established firms in a technological field. The more the first 
adopters are identified as 'fashion leaders', the higher is the probability of a locational cascade occurring, with cognitively close firms gathering in order to benefit from the cluster's growing reputation and geographical charisma. Proposition 2 is validated by the model as well. Indeed, depending on the respective weight of the informational and network effects, clusters will display diametrically opposite dynamic stability properties. When the informational effect prevails, the aggregate outcome does not converge on the 1-norm location and is highly unstable, unlike the network effect which engenders a strong dynamic stability of the 1-norm location. Of course, these results are highly sensitive to the assumptions on our formal configurations of location decision externalities, particularly to the ones concerning the small variations of $p(2)$. However, as in the social interaction models à la Schelling or Granovetter, these results show that there is no direct correspondence between individual preferences for places and the emerging collective structure. Again, this is consistent with empirical evidence on long-term performances cluster's. The colocation of complementary (and so cognitively distant) firms is particularly suited to the network-based management of intended knowledge spillovers. In technological fields where the composite dimensions of innovations require that different pieces of compatible knowledge are put together through colocation, firms can improve their external knowledge accessibility without reducing strongly their internal knowledge appropriation. Conversely, when the informational and reputational effects prevail, the outcome of colocation can display an excess of cognitive proximity so that the risks of unintended spillovers engender knowledge under-appropriation, a climate of mistrust, as well as tensions on the local labor market. Finally, the balance between these two effects could represent a suitable indicator of the dynamic stability of clusters.

Our results corroborate the current growing trend which acknowledges that clusters are not a panacea (Martin and Sunley, 2003) for knowledge-based economies. This trend is confirmed by a recent related literature according to which the geographical charisma of clusters is not a condition of their aggregate performance (Appold, 2005; Vicente and Suire, 2007), and that the evolving knowledge and network structures of clusters are an appropriate yardstick of clusters' life cycles (Menzel and Fornhal, 2007; Ter Wal and Boschma, 2007).

\section{Acknowledgements}

We thank Stephen Appold, Phil Cooke, Yan Dalla Pria and Sébastien Chantelot for their helpful comments and the fruitful discussions we had with them. This research has received financial support from the EURODITE Project (Regional Trajectories to the Knowledge Economy: A Dynamic Model, Sixth Framework Program, contract no 006187).

\section{References}

Antonelli, C. (2006) The business governance of localized knowledge: an information economics approach for the economics of knowledge. Industry \& Innovation, 13: 227-261.

Aoki, M. and Takizawa, H. (2002) Information, incentives, and option value: the silicon valley model. Journal of Comparative Economics, 30: 759-786.

Appold, S. (2005) The location patterns of U.S. industrial research: mimetic isomorphism, and the emergence of geographic charisma. Regional Studies, 31: 17-39.

Arthur, W. B. (1990) Silicon Valley locational clusters, why do increasing returns imply monopoly. Mathematical Social Sciences, 19: 235-251. 
Banerjee, A. (1992) A simple model of herd behavior. Quarterly Journal of Economics, 3: 797-817.

Bikhchandani, S., Hirshleifer, D., Welch, I. (1998) Learning from the behavior of others: conformity, fads, and informational cascades. Journal of Economic Perspectives, 12: 151-170.

Boschma, R. A. (2005) Proximity and innovation: a critical assessment. Regional Studies, 39: $61-74$.

Boschma, R. A. and Lambooy, J. G. (1999) Evolutionary economics and economic geography. Journal of Evolutionary Economics, 9: 411-429.

Boschma, R. A. and Frenken, K. (2006) Why is economic geography not ann evolutionary science? Towards an evolutionary economic geography. Journal of Economic Geography, 6: 273-302.

Boschma, R. A. and Martin, R. (2007) Editorial: Constructing an evolutionary economic geography. Journal of Economic Geography, 7: 537-548.

Boschma, R. A. and Iammarino, S. (2007) Related variety and regional growth in Italy. SPRU working papers series, no. 162. Brighton: SPRU.

Breschi, S. and Lissoni, F. (2001) Knowledge spillovers and local innovation systems: a critical survey. Industrial and Corporate Change, 10: 975-1005.

Brossard, O. and Vicente, J. (2007) Cognitive and relational distance in alliances networks: evidence on the knowledge value chain in the European ICT sector. Summer DRUID Conference, Copenhagen.

Cooke, P. (2001) Regional innovation systems, clusters, and the knowledge economy. Industrial and Corporate Change, 10: 945-974.

Cox, J. T. and Durrett, R. (1991) Non linear voter models. In R. Durett (eds) Random walks, Brownian motion and interacting particle system. Boston: Birkhauser.

Dalla Pria, Y. and Vicente, J. (2006) Interactions mimétiques et identité collective: gloire et déclin du Silicon Sentier. Revue Française de Sociologie, 47: 293-317.

David, P. (1988) Putting the past into the future of economics. Technical Report 533, Institute for Mathematical Studies in the Social sciences, Stanford University.

DiMaggio, P. J. and Powell, W. W. (1983) The Iron Gage revisited: institutional isomorphism and collective rationality in organizational fields. American Sociological Review, 48: 147-160.

Fleming, L. and Marx, M. (2006) Managing creativity within small worlds. California Management Review, 48: 6-27.

Frenken, K., van Oort, F.G., Verburg, T. (2007) Related variety, unrelated variety and regional economic growth. Regional Studies, 41: 685-697.

Geroski, P. A. (2000) Models of technology diffusion. Research Policy, 29: 603-625.

Granovetter, M. (1978) Threshold models of collective behavior. American Journal of Sociology, 83: $1420-1443$.

Hedstrom, P. (1998) Rational imitation. In R. Swedberg (ed.) Social Mechanisms: an Analytical Approach to Social Theory, pp. 306-327. Cambridge: Cambridge University Press.

Katz, M. and Shapiro, C. (1985) Network externalities, competition and compatibility. American Economic Review, 3: 424-440.

Kirman, A. (1997) The economy as an interactive system. In K. J. Arrow, L. Blume, S. Durlauf (eds) The Economy as an Evolving Complex System II. Redwood City, CA: Addison-Wesley.

Kogut, B. (1988) Joint ventures: theoretical and empirical perspectives. Strategic Management Journal, 9: 319-332.

Leibenstein, H. (1950) Bandwagon, snob, and Veblen effects in the theory of consumer's demand. Quarterly Journal of Economics, 64: 183-207.

Longhi, C. (1999) Networks, collective learning and technology development in innovative high technology regions: the case of 'Sophia-Antipolis'. Regional Studies, 33: 333-342.

Longhi, C., Lazaric, N., Thomas, C. (2004) From geographical to organized proximity: the case of the Telecom Valley in Sophia Antipolis, 4th Congress of Porximity Economics, Marseille.

Lopez Pintado D. and Watts, D. (2008) Social influence, binary decisions and collective dynamics. Rationality and Society, 20: 399-443.

Manski, C. F. (2000) Economic analysis of social interactions. Journal of Economic Perspectives, 14: 115-136.

Martin, R. and Sunley, P. (2003) Deconstructing clusters: chaotic concept or policy panacea? Journal of Economic Geography, 3: 5-35. 
Menzel, M. P. and Fornahl, D. (2007) Cluster life cycle: dimensions and rationale of cluster development. Jena Economic Research Papers, Max Plank Institute of Economics.

Nooteboon, B. (2000) Learning by interaction: absorptive capacity, cognitive distance and governance. Journal of Management and Governance, 4: 69-92.

Nooteboom, B. (2006) Innovation, learning and cluster dynamics. In B. Asheim, P. Cooke, R. Martin (eds) Clusters and Regional Development, pp. 137-163. London: Routledge.

Nooteboom, B. and Woolthuis, R. K (2005) Cluster dynamics. In R. A. Boschma and R. Kloosterman (eds) Learning from Clusters: A Critical Assessment, pp. 51-68. Dordrecht: Springer-Verlag.

Orléan, A. (2006) Mimetic interactions. In J. Lesourne, A. Orléan, B. Walliser (eds) Evolutionary Microeconomics. Berlin: Springer.

Quah, D. (2000) Internet cluster emergence. European Economic Review, 44: 1032-1044.

Saxenian, A. (1994) Regional Advantages: Culture and Competition in Silicon Valley and Route 128. Cambridge: Harvard University Press.

Schelling, T. C. (1978) Micromotives and Macrobehavior. New-York: Norton.

Schelling, T. S. (1971) Dynamic models of segregation. Journal of Mathematical Sociology, 1: $143-186$.

Sorenson, O., Rivkin, J. W., Fleming, L. (2006) Complexity, networks and knowledge flow. Research Policy, 35: 994-1017.

Spence, M. (1974) Competitive and optimal responses to signals: an analysis of efficiency and distribution. Journal of Economic Theory, 3: 296-332.

Strang, D. and Macy, M. W. (2001) In search of excellence: fads, success stories, and adaptive emulation. American Journal of Sociology, 107: 147-182.

Ter Wal, A. and Boschma R. (2007) Co-evolution of firms, industries and networks in space. Papers in Evolutionary Economic Geography, Utrecht University.

Vicente, J. and Suire, R. (2007) Informational cascades vs. network externalities in locational choice: evidences of 'ICT Clusters' formation and stability. Regional Studies, 41: 173-184.

Vicente, J., Dalla Pria, Y., Suire, R. (2007) The ambivalent role of mimetic behavior in proximity dynamics: evidence from the 'Silicon Sentier'. In J. Surinach \& alii (eds) Knowledge Externalities, Innovation Clusters and Regional Development, pp. 92-110. Northampton, MA: Edward Elgar.

Watts, D. (2006) The collective dynamics of belief. Working paper, Columbia University, forthcoming in V. Nee and R. Swelberg (eds) The Spirit of Capitalism. Stanford: Stanford University Press. 